\title{
The effect of the family physician plan on the performance of the medical and health centers of the Ghorveh city
}

\author{
Reza Ramazani ${ }^{1, *}$, Mohamad Khaledian ${ }^{2, * \star}$, Shahram Tofighi ${ }^{3}$, \\ Mohamad Reza Malaki ${ }^{4}$ \\ ${ }^{1}$ Kurdistan University of Medical Sciences, Sanandaj, Iran \\ 2Department of Psychology, Payame Noor University, PO BOX 19395 - 3697, Tehran, I.R. of Iran \\ ${ }^{3}$ Center for Research and Managing Health, Baqiyatallah University of Medical Sciences, \\ 1435814717 Tehran, Iran \\ ${ }^{4}$ Faculty of Management and Information, Tehran University of Medical Sciences, \\ 1995614111 Tehran, Iran \\ *,**E-mail address: Ramazani1345@gmail.com , Mohamad_khaledian22@yahoo.com
}

\begin{abstract}
The aim of the present research is to investigate the effect of the family physician plan on the medical and health centers of Ghorveh. The type of the research is semi empirical and is applied in nature. The research universe includes 15 medical and health centers of Ghorveh. The tools for collecting the data were information collection forms of the available statistical forms. The findings revealed there was a meaningful difference $(\mathrm{P}<0 / 001)$ with regards to the performances among the average monthly services in 2005 and 2009 at the 15 centers under study in 2005 (prior to the implementation of the plan) and in 2009 (at the time of the implementation of the plan). The performance at such centers in 2009 with regards to the mentally ill patients under care has decreased substantially.
\end{abstract}

Keywords: Family physician; Medical and health centers; mentally ill patients; under care

\section{INTRODUCTION}

Health and security are considered as primary rights of every individual in the society which governments are obliged to provide them for all the people of the society. The idea of the primary care and health services was a revolution formed in the system for providing services related to health that allowed for the design, the implementation, expansion and promotion of it in the country. Now that the insurance system for the rural people has been approved by the Islamic council parliament, the integration of the so-called family physician plan with the larger medical and health networks of the country is provided. Based on this fundamental measure, the family physician team assumes full responsibility of the people and families covered by the plan (Ministry of Health, 2008). The plan implemented on September 
2006 with the goal of promoting the health level and increasing the accessibility of the rural people, nomads and the cities under 20000 residents to the firs level health services, has been one of the top priorities of the Ministry of Health, treatment and medical education. In 2006,325 billion Rials (almost 1 million Dollars) and in 2007 to 2009, 6390 billion Rials (19 million Dollars) were allotted for the plan (Ministry of Health, 2009). One of the common ways for managing services and guiding patients appropriately in the health system is to use the family physician. This issue has a long tradition in countries having a national health system through public coverage where the family physician act as the protector at the entrance point of the system for securing health services in order to refer the patients in need of special care to higher levels in addition to providing such services (Karimi, 2008).

The contribution of the family physician primary care to the health and care systems is well established (Franks and Fiscella, 1998). According to the memorandum of understanding between the ministry of health, treatment and medical education and ministry of welfare, health networks as the contractors and general insurance bureaus for medical services as managers are bound to provide family physician services to rural places and cities below 20000 residents at the first level of the medical and health network equivalent to service packages including medical, drug, gynecological, nursing, laboratorial and radiology services to the people covered (Ministry of Health, 2009). In this plan, an approach to health is the pivot of the physician activities and the general objective of such a plan is to maintain and promote the health level of the society and to offer health services within the defined package to the individual, family, population and the society covered irrespective of differences in age, sex, economic social characteristics as well as the danger resulting from diseases (Iran ministry of health, 2005).

The family physician, in addition to treating diseases, instructions and necessary consultations for preventing diseases offers an acceptable physical and mental level ${ }^{1}$ (Asefzadeh and Rezapour, 2005). With several years passed since the implementation of the plan in the country, no special research regarding the performances has been conducted. The research aims to investigate and compare performances by the medical and health centers at the time of the implementation of the plan and prior to that at such centers of the Ghorveh city so that planners, policy makers and executives know about the implementation of the plan as well as applied and scientific research. The research always attempts to reflect advantages and disadvantages of the plan for future planning processes in order that rational decisions are made.

\section{MATERIAL AND METHODS}

The type of the research is semi empirical and is applied in nature. The research universe includes 15 medical and health centers of Ghorveh. 15 centers were put under study since data of 15 medical and health centers were available. Data were obtained through information collection forms. Data under study including patients seen by doctors, price of drugs taken, injection and bandage operations done were obtained from available bureaus at medical and health centers under study as well as data collected through touring rural places through instructors bureaus of health centers by obstetric specialists.

\footnotetext{
1 the College of Family Physician of Canada.the role of family doctors in public health and December 2005.available fom url://www.cfpc.ca/local/files/communications/role_fam_doc_de c05.pdf.
} 
Data obtained from the patients suffering from diabetes, blood pressure under care were collected from available statistical forms at the health center of Ghorveh and by the researcher. Concerning the price of drugs taken in 2009 and based on the inflation price, the medical and health items were calculated in the base year of 2005 and the comparison was performed. Data relating to the performances under investigation for the years of 2006 and 2009 were collected from among a total of 15 medical and health centers for at least 6 months and for a maximum of 1year and 147 months in total. Thus, data were entered into the SPSS software version 16 and were analyzed by an independent T-test. Meantime, to describe the data, descriptive statistics were applied.

\section{FINDINGS}

The findings revealed there was a meaningful difference ( $\mathrm{P}<0 / 001)$ with regards to the performances among the average monthly services in 2005 and 2009 at the 15 centers under study in 2005 (prior to the implementation of the plan) and in 2009 (at the time of the implementation the plan).

For mentally ill patients under care, at the time of the implementation the plan, fewer patients had been identified and put under care and for the others; the performances were given like the following table.

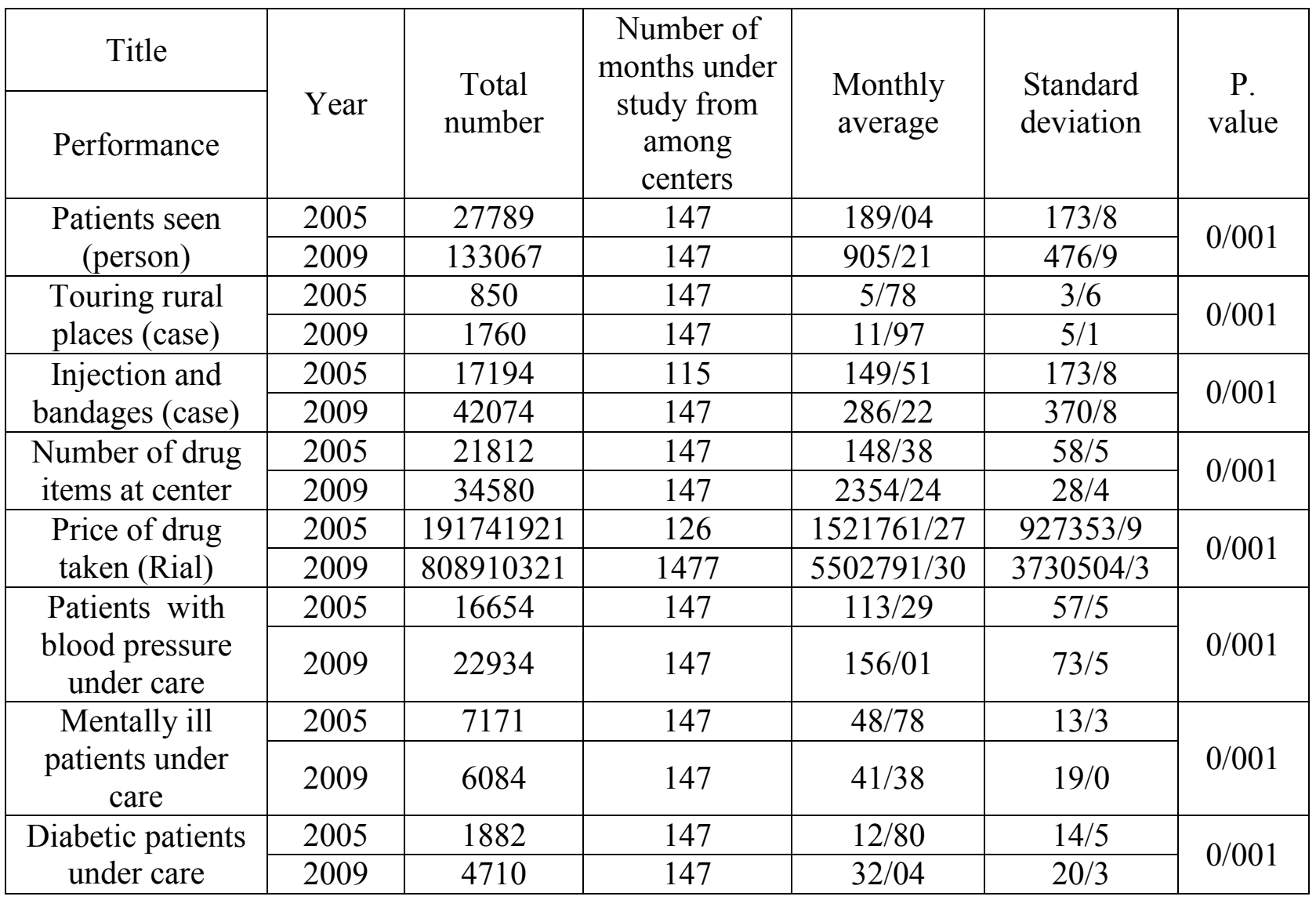




\section{DISCUSSION AND CONCLUSION}

The research aims to investigate and compare performances by the medical and health centers at the time of the implementation of the plan and prior to that at medical and health centers of the Ghorveh city. The performance at such centers in 2009 with regards to the mentally ill patients under care has decreased substantially. In such a way, the number of mentally ill patients placed under care was 6084 in 2009 which in comparison to 7171 patients put under care in 2005 shows that not only more patients were not placed under care at the time of the implementation of the plan, but also the number indicates a considerable reduction. This is a warning to health officials to take care the plan does not cause the integrated programs to be forgotten. The performance by the centers regarding the patients seen at the time of the implementation of the plan compared to the time prior to it was 4/78 times and the price of the drugs taken at such centers was $4 / 21$ times. These performances indicate a higher improvement compared to the other performances. Thus, this reflects the plan is treatment-oriented and is an indication of the pressures by the receivers for the services on the suppliers. The performance of the conducted village touring was $2 / 07$ that indicates a higher accessibility of the people to physicians and health services. On the other hand, performances concerning injections and bandages, diabetic patients under care and patients with high blood pressure under care were 2/44, 2/50, 1/37 times respectively.

As noted and in accordance with the findings, the implementation of the plan has resulted in improving the performances under investigation excepting mentally ill patients by the medical and health centers. However, an increase in the medical and health performance has not been correspondent or equal, in such a way, most activities of the health and medical centers at the time of the implementation of the plan were concentrated on visiting patients and providing drug services and though the other performances under study have increased compared to the time prior to the plan, the performance regarding mentally ill patients under care has reduced which this is not in line with their medical needs. It is recommended that planners provide doctors needed and monitor programs relating to health care services to mentally ill patients. Because, they obtained results relate only to one city, indicating declining results, it is recommended that similar studies be conducted in other cities and provinces so that the effect of the family physician plan is determined.

\section{Acknowledgment}

Researchers appreciate obstetric experts of the medical and health centers for assisting us with collecting data.

\section{References}

[1] Asefzadeh S., Rezapour A., Editors health administration Hadis Emroz press, 2005.

[2] Franks P., Fiscella K., J. Fam. Pract. 47(2) (1998) 105-109.

[3] Iran Ministry of Health administrative guide direction of family physician, 2005.

[4] Karimi M., Village treatment insurance, Ashraqia publication, Tehran, 2008, pp. 146-149. 
[5] Ministry of Health, family physician guidelines and rural insurance, copyright 8, 2008.

[6] Ministry of Health, family physician guidelines and rural insurance, copyright 9, 2009.

( Received 03 June 2013; accepted 09 June 2013 ) 